\title{
Topology Optimization of A Tensile Test SPECIMEN
}

\author{
BogreKCI, I., DeMIRCIOGLU, P., SUCUOGLU, H.S., \\ Altun, E., SAKar, B., DURAKBASA, M.N.
}

Abstract: The aim of this study is to analyze the impact of altered geometries on structural strength using static structural analysis. The tensile test specimens were created using solid state modelling in Autodesk Inventor Software and analysed with Siemens NX Software. Topology optimization was done in Autodesk Fusion 360. Certain amounts of incavation was applied. This is a significant improvement for weight-saving and complete design. After optimization, obtained data from first design were recorded and compared. Incavation parts were removed following topology optimization and then second design was created. Following the analysis of the second design, it was decided that a new design was needed. As a consequence, the third design was created. The analysis results of these three designs were compared with each other. As a result of the comparison, it was observed that the second design was $34.28 \%$ lighter than the original specimen. However, in the second design, regions with high stress values were existed. Therefore, the third design was created. The third design is $21.43 \%$ lighter than the original specimen, and the regions with high stress value have disappeared compared to the second design. Thus, the aim is achieved in terms of material savings.

Key words: Computer aided design, Computer aided engineering, Generative design, Shape optimization, Solid state modelling, Tensile test, Topology optimization.
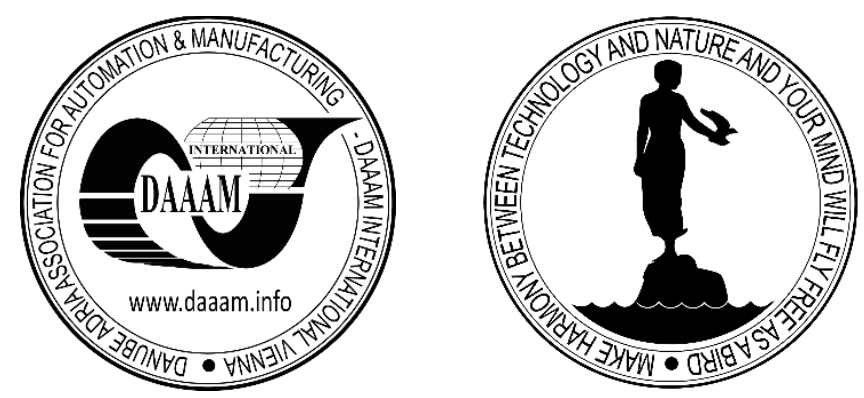

Authors' data: Prof. Dr. Bogrekci, I[smail]; Prof. Dr. Demircioglu, P[inar]*; Dr. Sucuoglu, H[ilmi Saygin]*; Altun, E[mre]*; Sakar, B[ilge]*; Durakbasa, N[uman M. ${ }^{* *}$; *Aydin Adnan Menderes University, Aydin, Turkey, ** Vienna University of Technology, A-1060, Vienna, Austria, pinar.demircioglu@ adu.edu.tr

This Publication has to be referred as: Bogrekci, I[smail]; Demircioglu, P[inar]; Sucuoglu, S[aygin]; Altun, E[mre]; Sakar, B[ilge] \& Durakbasa, N[uman] (2020). Topology Optimization of a Tensile Test Specimen, Chapter 08 in DAAAM International Scientific Book 2020, pp.099-112, B. Katalinic (Ed.), Published by DAAAM International, ISBN 978-3-902734-27-3, ISSN 1726-9687, Vienna, Austria DOI: $10.2507 /$ daaam.scibook.2020.08 
Bogrekci, I.; Demircioglu, P.; Sucuoglu, S.; Altun, E.; Sakar, B. \& Durakbasa, N.: ...

\section{Introduction}

Topology optimization task is to find the best distribution of material for computing optimal location, shape, size and connectivity of holes in a design domain. It is most general in the hierarchy of structural optimization and there is no constraint on size and boundary of design domain, which gives engineers more design freedom and search space to look for optimal solution especially during the initial design phase (Voruganti et al., 2019).

Optimization; within restricted conditions can be defined as the ideal solution to the problem. Increasing the use of optimization techniques was also reflected in the design process. The topology of the part designed with structural optimization is aimed to be enhanced in size and shape (Chu et al., 1997). Topological optimization is also performed by changing the size and shape optimization of the part in a specified design space of the part. As a result of research, it has been observed that structure performance increases significantly regard to topology optimization.

There are many methods for the production of various products in the industry. As technology develops, manufacturers are starting to use systems that are most suitable for their purposes in line with their own production.

Manufacturers have been able to produce rapid, more precise sizes and more economically than ever before with the integration of CAD/CAM (computer aided design/computer-aided manufacturing) technologies into the market. production is a process by passing through various manufacturing methods of the raw material and takes its final form. In the used machining methods waste occurs and therefore some of the used raw material is disposed as a scrap even with low prices, thus damage is minimized. However, waste in high-tech industries such as aviation means a huge cost. Considering this, research have focused on 3D printer technologies. 3D printers have found a great response in the industry since they first came onto the market. Regarding to these devices besides prototype production, final production can be carried out.

Although plastic derivatives were generally used as raw material in 3D printers at first, the need for 3D printers that produce metal is increasing day by day. Considering the current studies, studies on welding technology in metal product production stand out. WAAM helps to reduce time and cost due to reduction in manufacturing lead time and waste material. In their study (Busachi et al., 2015) worked on the design of a WAAM (Wire + Arc Additive Manufacturing - Tel + Arc Additive Manufacturing) based manufacturing system for the defense industry. In their work, the authors mention that this technology greatly reduces the unnecessary use of raw materials. They stated that this rate decreased from $90 \%$ to $10 \%$. 3D parts are produced by arc welding with WAAM, thus saving time and materials

In this study, topology optimization was performed on Autodesk Fusion 360 without applying too much reduction of the safety coefficient by applying the required load of the tensile test sample. With the optimization, the weight of the tensile test specimen was reduced. Thus, less material was used and the structure was aimed to reach the optimum form within the required constraints. Thus, it is aimed to use less material and to produce it in a shorter time. The impact of incavation in the test specimen on strength was determined by analysing the obtained forms. 


\section{Literature Review}

It is aimed to bring the part designed with structural optimization technology closer to the ideal in topology, size and shape. In size and shape optimizations, the optimization related to the size and shape of the piece is performed, while in topology optimization the application is made in a design area determined. Studies in topology optimization were increased recent years, thus it is possible to find many studies related to topology optimization in the literature.

With topology optimization, which is a special case of shape optimization, certain variables and limitations can be determined and the optimum design can be achieved by performing analysis with the topological optimization method under the target function. In a production studio in Melbourne, topology optimization was applied to improve a traditional piston model. It was determined that the model obtained by optimization is $23.5 \%$ lighter than the existing piston model. The development process of the application is shown in Fig. 1.

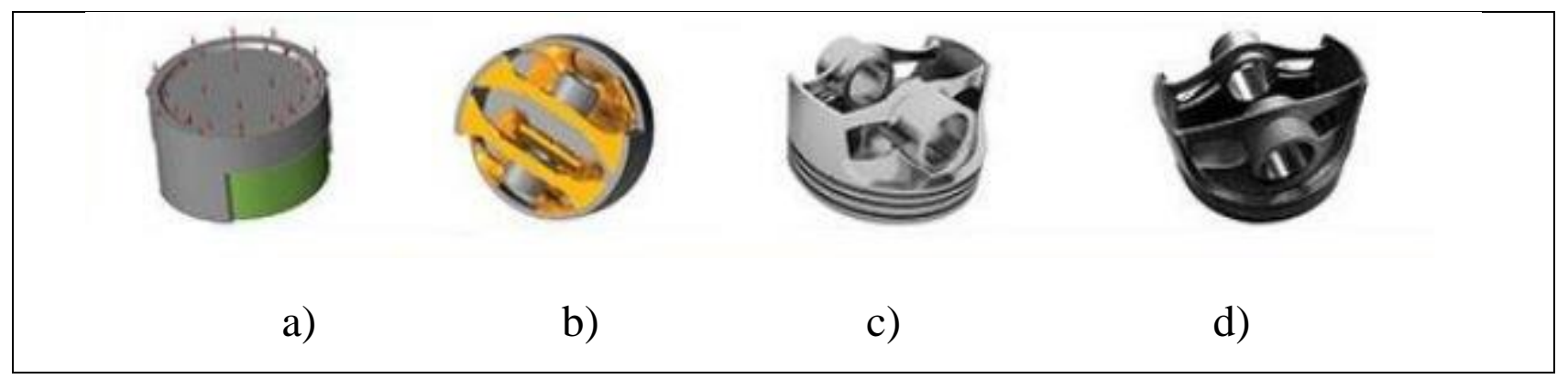

Fig. 1. Application of topology optimization on a traditional piston (Le, 2017). (a) shows the design space. A design space is the initial part from that material is removed till a final form is reached throughout optimization. Any part that's a design space is going to be reshaped throughout optimization, whereas any part that's not a design space can stay as it is, (b) shows Solidthinking inspire optimized output. As a result of the optimization parts that need to be removed are shown, (c) shows the refinement in CAD. As a result of the optimization parts that need to be removed were removed via a CAD Software, (d) shows the Final piston produced with additive manufacturing.

To give support the RUAG Space Switzerland design, it can be given as an example the antenna support arm for the application of topology optimization in the space industry. The surface modelling process was carried out with Solid Thinking Evolve and after 4 weeks, the new design of the antenna support arm was produced with 3D printers of RUAG. Final product was half of original weight, stronger structure and cost saving for launching into space. 


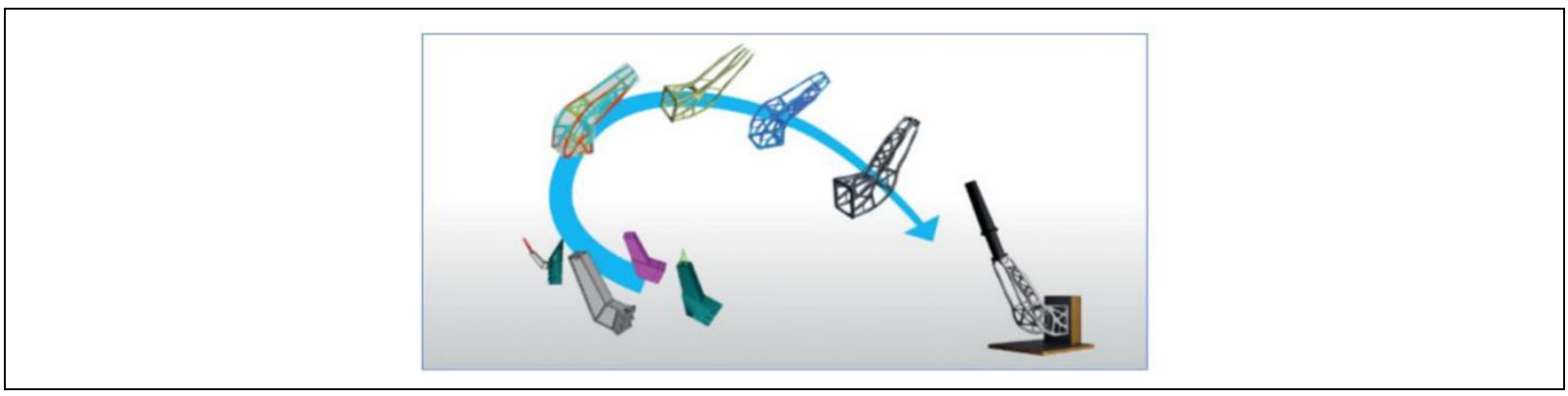

Fig 2. Design process of antenna support arm for RUAG Space (Le, 2017).

(Saleem et al., 2008) worked on the mathematical model of topology optimization due to the increase in demand for materials with high strength and low weight. The topology optimization of desired part was examined. Structural analysis that made in Ansys after optimization were repeated. Optimized materials and materials that are not optimized were compared. As a result of the study, it was observed that the new design proposal was more reliable and lightweight.

In the study conducted by (Yaban, 2012) an evolutionary optimization algorithm was developed for topology optimization of an elastic aircraft part under the defined load and boundary conditions and created a computer program in visual basic language. The created program was run simultaneously with MSC.PATRAN and MSC.NASTRAN programs, and results were obtained for the aircraft part pressure wall, and with these results, the aircraft part Topology Optimization was examined. As a result of the study, it was observed that the weight diminished by $25 \%$.

In the study conducted by (Aktepe, 2011) for the optimal design of wind turbine blades, it was examined wind turbine blades topology optimization using Pareto Academic. As a result of the study, a 30-40\% volumetric decrease was achieved in the structure.

In the study conducted by (Y1ldiz, 2017), the wishbone used in the suspension systems of passenger cars was designed optimally using radial-based functions metamodelling method and interior search algorithm. In the optimization study, four design variables were determined according to the results of topology optimization, and a hundred different wishbone models were created with the Latin hypercube method so that the upper and lower limits of these variables were not violated. The stress values on the wishbone and the weight of each design were calculated by performing finite element analysis on the working conditions given for each design. According to the results, mathematical equations for stress and weight value were obtained by using radial-based functions. As a result of this study, the weight of the optimum design decreased by $28 \%$.

In his study, (Erol, 2019) was applied topology optimization of the upper torque arm component of the aircraft's body landing gear. Static analysis and topology optimization were applied to the upper torque arm component of the aircraft's body landing gear via Ansys Workbench, HyperWorks and sT softwares. Optistruct program was used to make necessary changes on the shape after topology optimization. As a result, the piece with a mass of $1.96 \mathrm{~kg}$ was reduced to $1.51 \mathrm{~kg}$ with SolidWorks in the 
final and $1.14 \mathrm{~kg}$ with sT inspire. This means a gain of $37.5 \%$ and $41.8 \%$, respectively, by mass.

In the study conducted by (Çalışkan, 2018) it is aimed to diminishing the weight of leaf spring bracket in Ford Transit model by topology optimization study. The structural analysis and displacement of the part before optimization and the structural analysis and displacement of the part designed after optimization were compared. Design has been examined with fatigue analysis. As a result of this, three designs were created. The desired result was obtained in the third design. A suitable design has been obtained in terms of displacement and fatigue criteria. It is also $18.25 \%$ lighter than the current design. This shows that the third design is the best design in terms of material saving.

In the study carried out by (Iş1k, 2009) topology optimization was performed with finite element method by modelling the flange yoke part found in heavy commercial vehicles. Static analysis of the optimal part geometry was performed with Altair Optistruct software. Static structural analysis performed before optimization and static structural analysis performed after optimization were compared. As a result of the topology optimization the weight of the flange yoke has been diminished by around $12 \%$.

\section{Material and Method}

In this study; the impact of altered geometries on structural strength using PLA material by static structural analysis was analyzed. A certain amount of incavation was applied to tensile test specimens for comparison. The tensile test specimens were created using solid state modelling in Autodesk Inventor Software (Fig. 3).

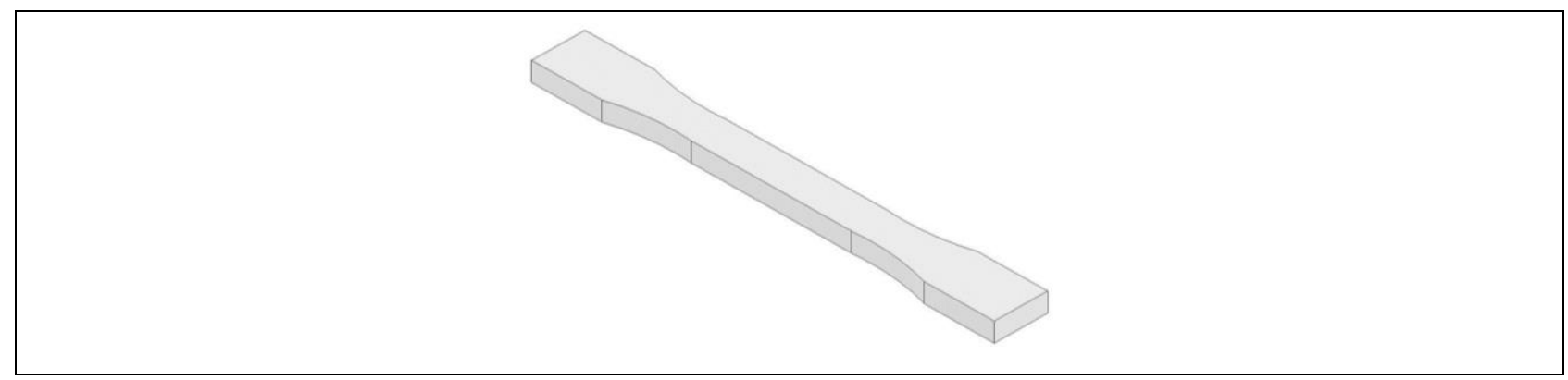

Fig. 3. Tensile test specimen.

Then PLA material was added to this created piece. After adding the material, its mass is approximately $0.022 \mathrm{~kg}$. $1100 \mathrm{~N}$ force was applied to the tensile test specimen during the analysis.

Topology optimization was applied to original tensile test specimen. \%40 incavation was achieved in topology optimization. To create a new geometry, incavation parts were removed following topology optimization. A new model was created after the necessary procedures were completed.

New model was analyzed by static structural analysis. Data obtained from analysis were recorded and compared with the original tensile test specimen's analysis data. 
Bogrekci, I.; Demircioglu, P.; Sucuoglu, S.; Altun, E.; Sakar, B. \& Durakbasa, N.: ...

3.1 Design of tensile test specimen

The tensile test specimen was designed according to design type 1 of ASTM D638-14. Dimensional details of tensile test specimen were given in Tab. 1.

\begin{tabular}{|l|c|}
\hline & 165 \\
\hline Geometry & 57 \\
\hline Total length (LO) & 19 \\
\hline Length of narrow section (L) & 13 \\
\hline Width of part (WN) & 76 \\
\hline Width of narrow section (W) & 7 \\
\hline Distance between grips (D) & Dimensions (mm) \\
\hline Radius of fillet (R) & \\
\hline Thickness (T) & \\
\hline
\end{tabular}

Tab. 1. Dimensions of tensile test specimen

\subsection{Analysis of Tensile Test Specimens}

Tensile test specimens were analysed using static structural analysis in Siemens NX Software. To obtain realistic values raw PLA material has been added. Physical and mechanical properties of PLA obtained from the literature were defined to the software (Tab. 2).

\begin{tabular}{|l|c|c|}
\hline \multicolumn{1}{|c|}{ Characteristic } & Unit & Amount \\
\hline Solid Density & $\mathrm{g} / \mathrm{cm} 3$ & 1.252 \\
\hline Tensile Strength & $\mathrm{MPa}$ & 59 \\
\hline Ultimate Tensile Strength & $\mathrm{MPa}$ & 73 \\
\hline Young Modulus & $\mathrm{MPa}$ & 1280 \\
\hline Poisson Ratio & - & 0.36 \\
\hline
\end{tabular}

Tab. 2. Physical and mechanical properties of PLA Işık (2009).

After material properties described above were defined to the program, model is meshed (Fig. 4). 


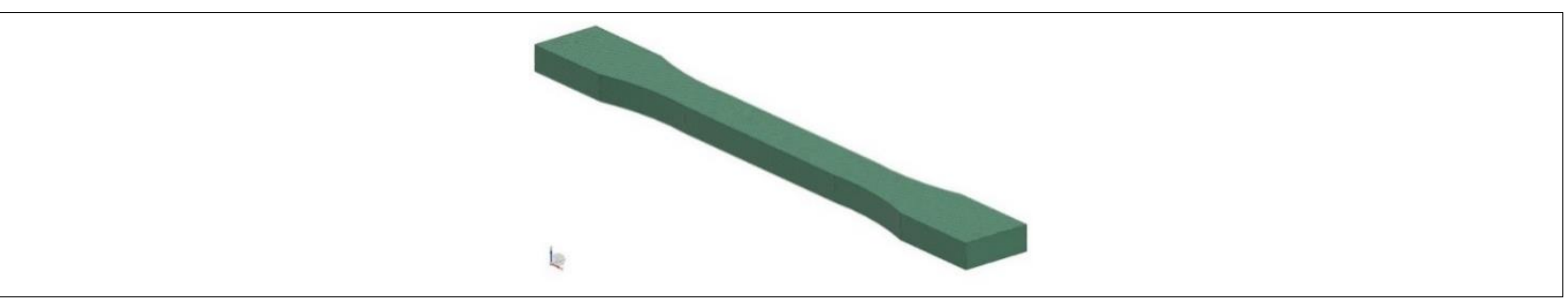

Fig. 4. Meshed view.

10-node (quadratic) mesh is used. Mesh properties are given in Tab. 3.

\begin{tabular}{|l|c|}
\hline \multicolumn{2}{|c|}{ Mesh Information } \\
\hline Total number of elements in the part & 87170 \\
\hline Total number of nodes in the part & 134255 \\
\hline Total number of Tetra10 elements in the part & 87170 \\
\hline
\end{tabular}

Tab. 3. Characteristics of Mesh.

$1100 \mathrm{~N}$ force was applied to tensile test specimens in static structural analysis via Siemens NX software (Fig. 5).

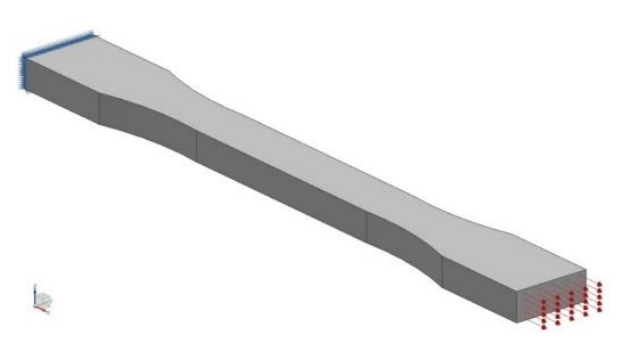

Fig. 5. Application of $1100 \mathrm{~N}$ force to the specimen.

\subsection{Topology Optimization}

Topology optimization aims to find the best material distribution within the framework of the given target functions and constraints.

In topology optimization solution, the target region is divided into finite elements IR2 or IR3. After this process, the solution is made iteratively according to the method chosen.

In order to formulate the topological optimization problem, a target function, design variables and state variables must be defined. Target function refers to the function that is desired to be maximum or minimum. A typical target function can be the stiffness or volume of the structure. Some structural design zones and state variables are linked to the defined target function. Design variables (x) define the design of the structure, for example it can represent geometry. The state variable (y) represents structural responses such as stress, displacement (Larsson, 2016). 
Bogrekci, I.; Demircioglu, P.; Sucuoglu, S.; Altun, E.; Sakar, B. \& Durakbasa, N.: ...

$$
\begin{aligned}
& \left\{\begin{array} { c } 
{ \operatorname { m i n } } \\
{ x } \\
{ \text { subjected to } }
\end{array} \quad \left\{\begin{array}{l}
\text { design constraint on } x \\
\text { state constraint on } y(x) \\
\text { equilibrium constraint }
\end{array}\right.\right. \\
& \begin{cases}\min & f(x) \\
x & g(u(x) \leq 0\end{cases}
\end{aligned}
$$

The state variable is expressed as $\mathrm{y}(\mathrm{x})$ depending on the design variable. The goal function is subject to design and state variable constraints to direct optimization to a desired solution. $\mathrm{g}(\mathrm{y})$ can be expressed as a state function that represents the state variable. Displacement in a given direction can be cited as an example. This situation function is formulated as $\mathrm{g}(\mathrm{y}) \leq 0$ when considering the constraint in the optimization task. In the discrete finite element problem, $\mathrm{g}(\mathrm{y}) \mathrm{g}(\mathrm{u}(\mathrm{x}))$ is represented as the displacement vector. In order to create the state function, the node displacement must be solved with the K stiffness matrix and the global load vector $f$.

$$
u(x)=K(x)^{-1} f(x)
$$

Equation 3 represents the linear elasticity formula of finite elements and is the rigidity matrix $\mathrm{K}(\mathrm{x})$ and the displacement matrix $\mathrm{u}(\mathrm{x})$ with the applied force of $f$. The aim here is to minimize the compliance and diminish the structure to the volume at the desired upper limit.

Compliance is the measure of the work done by the external force on the structure. It is the sum of the displacement in each element depending on the size of the load. Minimizing this size means minimizing the deterioration in the structure. That is to maximize stiffness (Larsson, 2016).

An optimum subset that is mathematically $\Omega$ mat $\subset \Omega$ is seeked. Here $\Omega$ is the possible design domain. The design variable is represented in this case by the density vector containing the element density. The local stiffness tensor $\mathrm{E}$ is formulated integral by combining with $\rho$.

$$
\begin{aligned}
& E(\rho)=\rho E_{0} \\
& \rho_{e}=\left\{\begin{array}{l}
1 \quad \text { if } e \in \Omega_{\text {mat }} \\
0 \text { if } e \in \Omega / \Omega_{\text {mat }}
\end{array}\right.
\end{aligned}
$$

And the volume constraint;

$$
\int \Omega \rho d \Omega=\operatorname{Vol}\left(\Omega_{m a t}\right) \leq V
$$

It is defined as. Here, $V$ represents the initial design domain. When $\rho_{\mathrm{e}}=1$, it is understood that it is filled with element and in $\rho_{\mathrm{e}}=0$, it is void element. In order to use a gradient based solution method, it is necessary to express the integer function as a continuous function. This is necessary for the density function to take a value between 
0 -1 (Bendsøe \& Sigmund, 2004). The most known way to spread the integer value is the SIMP (Solid Isotropic Material with Penalization) method. Thus, the density function;

$$
E=\rho^{\rho} E^{0}, \rho \in\left[\rho_{\text {min }}, 1\right], p>1
$$

Here $\mathrm{p}$ represents the penalizing factor, $\mathrm{p}$ values between $\mathrm{p}$ and punishment reach 0 or $1, \rho$ min is the lower intensity limit value to prevent singularity. Thus, the need to introduce a clear method of punishment is eliminated. For materials with a Poisson ratio of 0.3, it is recommended that $p \geq 3$ (Bendsøe \& Sigmund, 1999).

\section{Result and Discussion}

The Von misses yield criteria, one of the most common stress analysis criteria were taken as the basis. The static structural analysis results were compared with PLA's yield strength which is $59 \mathrm{MPa}$. As shown in the Fig. 6 maximum stress is found 13.349 $\mathrm{MPa}$ from analysis. When this value is taken into consideration, it is seen that the model is secure in terms of the force applied on it. In this optimization, it will be tried to find an optimum design that shows the same strength against the same force.

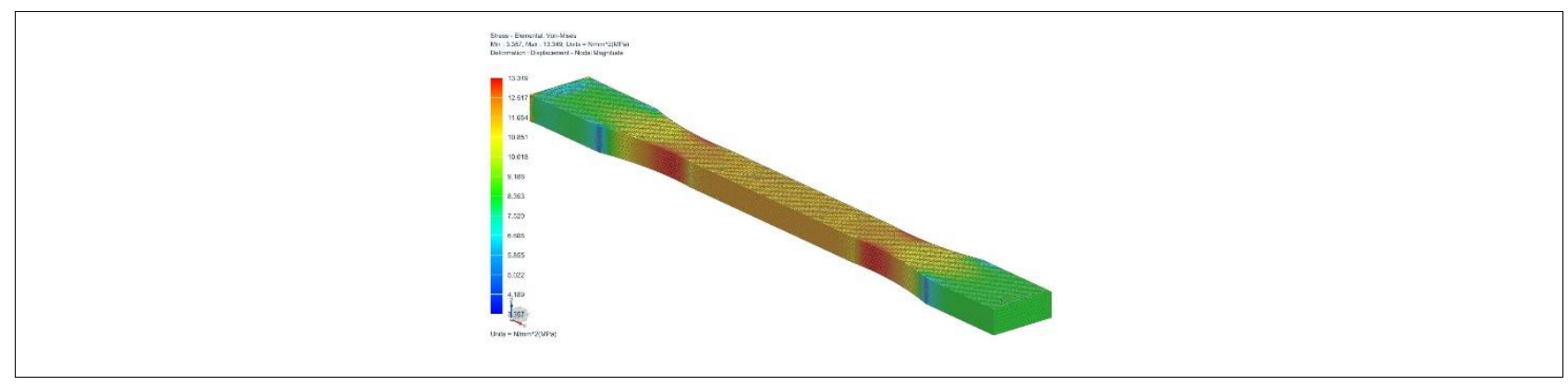

Fig. 6. Stress analysis result-Von Mises.

Displacement of the specimen on the $\mathrm{x}$ axis is given in Fig. 7.

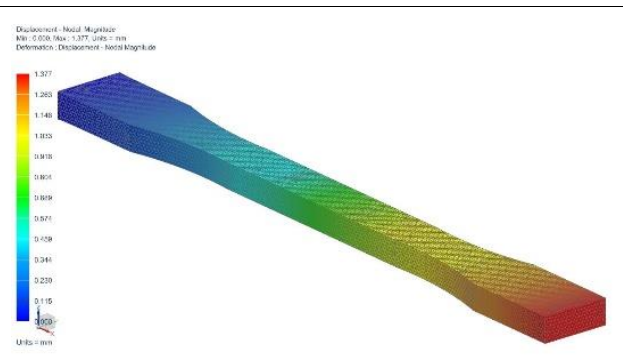

Fig. 7. Displacement on the $\mathrm{x}$ axis was calculated as $1.377 \mathrm{~mm}$.

Topology optimization was applied to original tensile test specimen in Autodesk Fusion 360. \% 40 incavation was achieved in topology optimization. The obtained form after topology optimization is given in Fig. 8. 


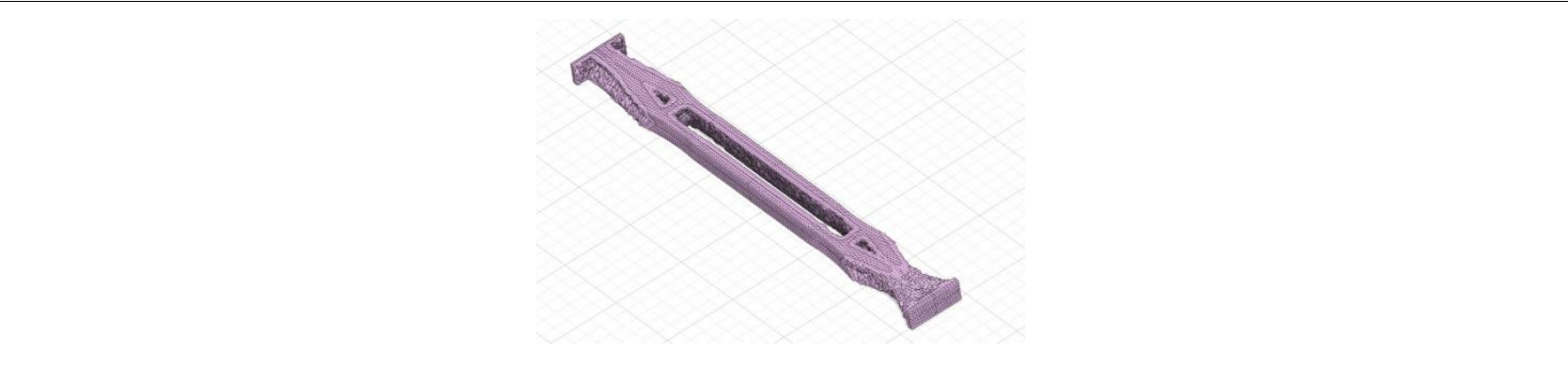

Fig. 8. Obtained form after topology optimization.

Arrangements were made on the figure to make the resulting from usable. Necessary arrangements were made on the obtained form as shown in Fig. 9.

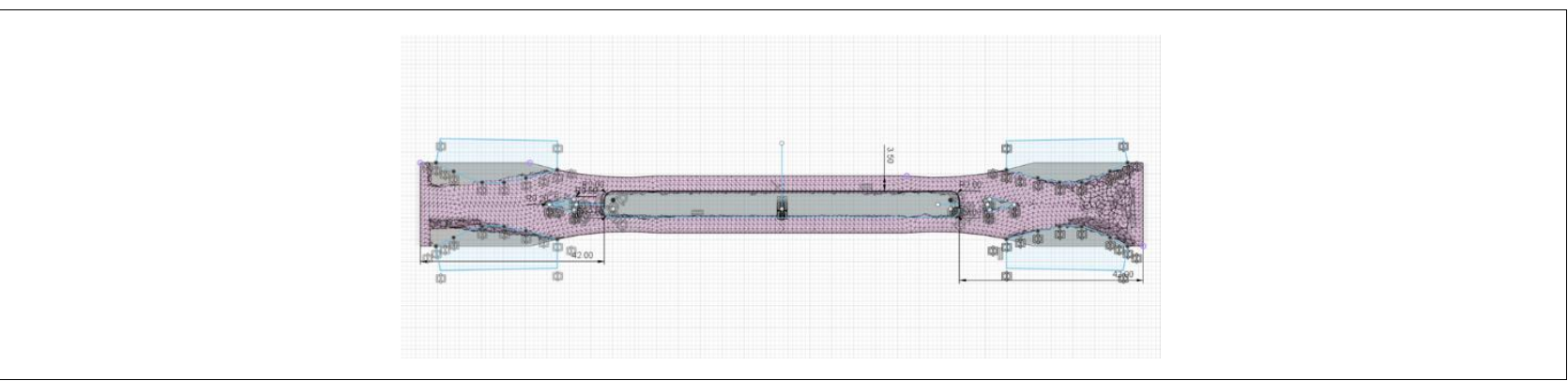

Fig. 9. Arrangements made on the obtained form.

A new model was created after the necessary procedures were completed (Fig. 10).

Fig. 10. The new model that created after the necessary procedures are completed.

Static structural analysis was applied to the new model created after topology optimization in order to make comparisons. As a result of the analysis, it is observed that the maximum stress $32.78 \mathrm{MPa}$ (Fig. 11). 


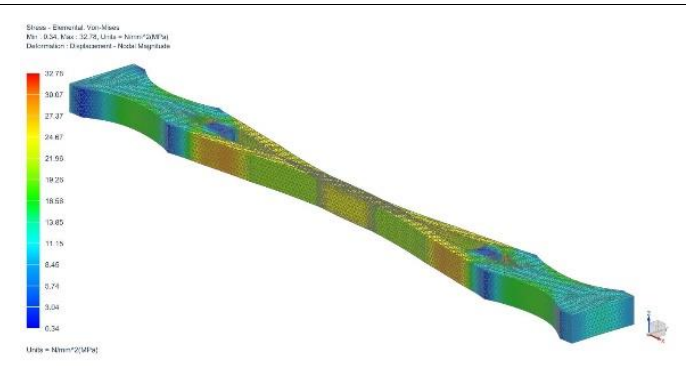

Fig. 11. Stress analysis result of second design.

The displacement in the $\mathrm{x}$ axis is $2.400 \mathrm{~mm}$. It is shown in Fig. 12.

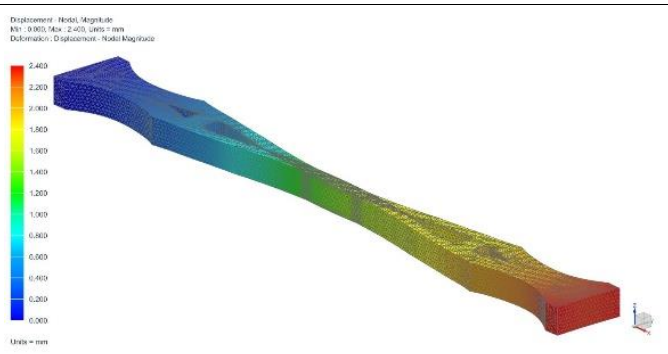

Fig. 12. Displacement in the $\mathrm{X}$ axis.

In regions with high stress value, it was necessary to make a new design again. In this way, a new design has been created. Third design is shown in Fig. 13.

Fig. 13. Third design.

Static structural analysis was applied to Third design. As a result, based on analysis of the re-designed specimen, the Max stress value was calculated as 23.04 Mpa (Fig. 14).

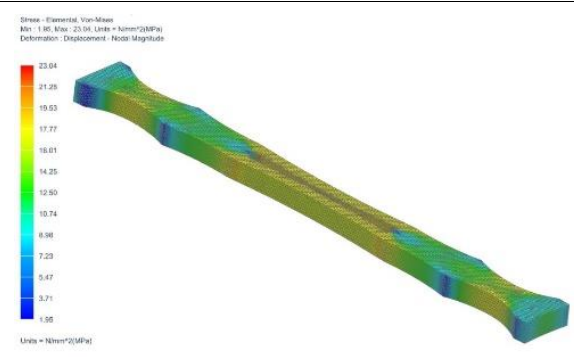

Fig. 14. Von Mises stress value is $23.04 \mathrm{Mpa}$. 
Comparison by results based on analysis of the original specimen and redesigned specimens are given in the Tab. 4.

\begin{tabular}{|l|c|c|c|}
\cline { 2 - 4 } \multicolumn{1}{c|}{} & \multicolumn{3}{|c|}{} \\
\cline { 2 - 4 } \multicolumn{1}{c|}{} & \multicolumn{3}{|c|}{ Analysis Results } \\
\cline { 2 - 4 } \multicolumn{1}{c|}{} & $\begin{array}{c}\text { Original } \\
\text { Specimen }\end{array}$ & 2. Design & 3. Design \\
\hline Stress (MPa) & 13.349 & 37.78 & 23.04 \\
\hline Displacement (mm) & 1.377 & 2.400 & 17.278 \\
\hline Mass (g) & 21.990 & 14.451 & 2.299 \\
\hline Safety Factor & 4.396 & 1.388 & \\
\hline
\end{tabular}

Tab. 4. Comparison of original specimen and redesigned samples.

From the table above, it is seen that the mass of the original specimen is 21.990 g. In the second design created after topology optimization, this mass decreased to $14.451 \mathrm{~g}$. This means saving 7.539 grams of material. Despite saving material in the second design, it is seen that the stress value has increased considerably. Third design was needed for to diminish this stress value.

As a result of this, the third design was created. In the Third Design, the stress value was calculated as $23.04 \mathrm{Mpa}$. The stress value of the third design is $14.74 \mathrm{MPa}$ less than the stress value of the second design. Although the stress was reduced, the mass increased by $2.826 \mathrm{~g}$ compared to the second design. $\% 21.43$ material-saving was achieved, which shows that we have achieved our goal in terms of material savings.

\section{Conclusion}

Nowadays, cost of the material is an important issue for the companies. The decreasing of the manufacturing and material costs can be an important advantage for these companies. In order to decrease these costs, the topology optimization can be an excellent tool. In this study, it was aimed to reduce the mass by applying topology optimization to the tensile test specimen. Topology optimization was applied to original specimen. \%40 incavation was achieved in topology optimization. Incavation parts were removed via a CAD program to obtain a new design.

Thus, the second design was created. In the second design, regions with high stress value were considered. A third design was created to eliminate these regions with high stress value. The analysis results of the original specimen and redesigned samples were compared. The third design is $4.713 \mathrm{~g}$ lighter than the first design, which corresponds $\% 21.43$. 
The main conclusions reached by the study are;

- Light weight

- Using less material with gaining from the mass, thus reducing the cost

- Reducing production time by using less material, thereby saving time.

- Optimized design.

Firstly, in this study, a new test piece was obtained at optimum values by applying topology optimization on the specimen using PLA material in the test specimen. New results can be obtained by applying this study to different types of materials. And the different results obtained can be compared among themselves.

Secondly, using the topology optimization method applied in this study, topology optimization can be applied for high cost and weight materials used in the field of industry, especially defence and aviation. In this way, by saving high cost and excess weight, great energy savings will be achieved at the same time.

Finally, in this study, the new test piece obtained by topology optimization can be tested in the laboratory using tensile test machine. And the experimental values measured here can be compared with the values obtained in the analysis program and new results can be obtained.

For further studies; it's planned to apply the topology optimization for different structures and shapes such as flanges, transmission elements etc. In these studies, structural strength analyses and experimental tests will be applied.

\section{References}

Aktepe, İ. (2011). Rüzgar Türbini Kanadının Optimal Tasarımı. M.Sc. Dissertation, Mechanical Engineering, Y1ldı Technical University, İstanbul.

Bendsøe, M. P. \& Sigmund, O. (1999). Material interpolation schemes in topology optimization. Archive of Applied Mechanics. Vol.69, No.9, pp. 635-654, ISSN: 14320681.

Bendsøe, M. P. \& Sigmund, O. (2004). Topology optimization: theory, methods and applications. Berlin: Springer-Verlag, ISBN 978-3-662-05086-6.

Busachi, A.; Erkoyuncu, J.; Colegrove, P.; Martina, F. \& Ding, J. (2015). Designing a WAAM Based Manufacturing System for Defense Applications. Proceedings of CIRP 37 - Understanding the life cycle implications of manufacturing, Online, ISSN: 22128271, pp. 48-53, Elsevier Procedia.

Çalışkan, B. (2018). Bir Ticari Taşıtın Makas Gözü Bağlantı Parçasının Optimizasyonu ve Yapısal Analizler İle Tasarımın Doğrulanması. M.Sc. Dissertation, Mechanical Engineering, İstanbul Technical University, İstanbul.

Chu, D.N.; Xie, Y.M.; Hira, A. \& Steven, G.P. (1997). On various aspects of evolutionary structural optimization for problems with stiffness constraints. Finite Elements in Analysis and Design, 24, 4,197-212, ISSN: 0168-874X.

Erol, B. (2019). Uçak Komponentlerinin Bilgisayar Destekli Malzeme Seçimi ve Topoloji Optimizasyonu ile Tasarımı. M.Sc. Dissertation, Material Science and Engineering, Ege University, İzmir. 
Bogrekci, I.; Demircioglu, P.; Sucuoglu, S.; Altun, E.; Sakar, B. \& Durakbasa, N.: ...

Farah, S.; Anderson, D. G. \& Langer, R. (2016). Physical and mechanical properties of PLA, and their functions in widespread applications-A comprehensive review. Advanced drug delivery reviews, Vol. 107, pp. 367-392, ISSN: 0169-409X.

Işık, E. (2009). Topoloji Optimizasyonu Çatallı Flanş Uygulaması. M.Sc. Dissertation. Construction and Manufacture Department of Mechanical Engineering, Dokuz Eylül University, İzmir.

Larsson R, (2016). Methodology for Topology and Shape Optimization: Application to a Rear Lower Control Arm. M.Sc. Dissertation, Department of Applied Mechanics, Chalmers University of Technology, Göteborg, Sweden.

Le, K. L. (2017). Generative Design with solidThinking Inspire, Bachelor Degree Thesis of Plastics Technology, Arcada University of Applied Sciences, Helsinki, Finland.

Saleem, W.; Lu, H. \& Yuqing, F. (2008). Topology Optimization-Problem Formulation and Pragmatic Outcomes by integration of TOSCA and CAE tools. Proceedings of the World Congress on Engineering and Computer Science, San Francisco, ISBN: 978-988-98671-0-2.

Voruganti, H. K.; Kumar, K. K.; Krishna, P. V. \& Jin, X. (Eds.) (2019). Advances in Applied Mechanical Engineering, Select Proceedings of ICAMER 2019, ISBN 978981-15-1201-8, Springer, Singapore.

Yaban, E. (2012). Bir Uçağın Basınç Duvarının Yapısal Optimizasyonu., M.Sc. Dissertation, Mechanical Engineering, Gazi University, Ankara.

Yıldız, A. (2017) Taşıt Elemanlarının Yapısal Optimizasyon Teknikleri ile Optimum Tasarımı. Politeknik Dergisi. 20, 319-323, E-ISSN 2147-9429. 